\title{
DETERMINAN ADVERSITY QUOTIENT DAN KEMAMPUAN BERPIKIR KRITIS DENGAN STRES PADA MAHASISWA YANG SUDAH BEKERJA
}

\author{
Riris Andriati ${ }^{1 *}$, Fenita Purnama Sari Indah ${ }^{2}$, Renti Yunita ${ }^{3}$ \\ ${ }^{1,3}$ STIKes Widya Dharma Husada Tangerang , Jl. Pajajaran No 1, Tangerang Selatan 15417, Indonesia \\ ${ }^{2}$ STIKes Kharisma Persada, Jl. Pajajaran No 1, Tangerang Selatan 15417, Indonesia
}






\section{PENDAHULUAN}

Mahasiswa yang sudah bekerja
kerap menunda kewajiban, karena
ketidaksiapan mahasiswa dalam
melaksanakan bermacam tuntutan yang
dimilikinya. Seseorang yang sudah masuk
dunia perkuliahan kerap tidak bisa
mengatur waktu yang digunakan. Waktu
dunia perkuliahan sangat berbeda dengan
jenjang pendidikan menengah sehingga
mahasiswa diharapkan mampu mengatur
waktu dengan benar, misal waktu untuk
kuliah, bermain, mengerjakan tugas serta
waktu untuk bekerja (Basri, 2017).

Stres merupakan salah satu cara otak dan tubuh manusia untuk merespon bermacam kondisi atau streser yang didalam nya. Stres adalah semua stimulus atau rangsangan baik secara instrinsik maupun ekstrinsik yang menyebabkan suatu respon biologis (Yanbaygi, Panahi, Sahraei, Johnston, 2017). Stres seringkali terjadi pada orang yang bekerja, maupun kegiatan perkuliahan yang dihadapi. Begitupun mahasiswa yang bekerja sambil kuliah mudah mengalami stres. Mahasiswa yang mengalami stres rentan terjadinya gangguan fisik, emosi, dan tingkah laku (Yanhi, 2015).

Ada beberapa faktor yang mempengaruhi seorang mahasiswa mengalami stres yaitu faktor akademis, faktor pribadi atau hubungan interpersonal dan faktor lingkungan belajar (Mustafa dkk, 2009). Mahasiswa bekerja lebih stres daripada tidak bekerja (Abdullah \& dan, 2011). Menurut Turkington (dalam Salam, 2015) stres muncul disebabkan oleh faktor finansial, sakit, manajemen waktu, pasangan, kehidupan sosial, masalah keluarga, kerja atau karir.

\section{Menurut WHO (World Health} Organization), angka kejadian stres tergolong cukup tinggi memperoleh lebih dari 350 juta penduduk di dunia dan berada di peringkat ke-4 penyakit di dunia (Ambarwati, Pinilih dan Astuti, 2017). Sumber stres bisa berasal dari berbagai hal, seperti krisis, frustasi, konflik, dan tekanan (Syamsuddin, 2017). Di Amerika, terdapat $75 \%$ orang dewasa menderita stres berat hingga jumlahnya meningkat dalam satu tahun terakhir (American Psychological Asscociation, 2013).

\section{Berdasarkan data RISKESDAS} (Riset Kesehatan Dasar) (2013), angka kejadian orang yang mengalami gangguan mental emosional di Indonesia adalah 6\%. Scakavitz (2011) menunjukkan bahwa di dunia prevalensi mahasiswa yang menderita stres berkisar 38-71\%, di Asia terdapat 39,6-61,3\% (Ambarwati, 2017).

Di Indonesia, sekitar 1,33 juta penduduk mengalami stres. Prevalensi mencapai 14\% dengan tingkat stres akut hingga 1- 
3\% dan stres berat mencapai $7-10 \%$ (Hidayat, B.A, 2012). Berdasarkan data Riskesdas (2018) di Provinsi Banten menunjukkan tingginya angka gangguan jiwa. Pada tahun 2018 angka kejadian gangguan mental emosional di Provinsi Banten mencapai 14\%, gangguan jiwa berat $0,57 \%$, dan depresi $8,7 \%$.

Menurut Stoltz, Adversity Quotient merupakan kemampuan berpikir dalam melawan keadaan yang sulit. Hasil penelitian selama 19 tahun dan proses selama 10 tahun adalah suatu hal penting terhadap pemahaman perihal apa yang dibutuhkan seseorang agar menggapai keberhasilan (Stoltz, dalam Fadilah, 2018). Stolz beranggapan bahwa antara banyaknya kekuatan yang dimiliki seseorang, salah satunya yaitu seberapa jauh seseorang bisa bertahan menghadapi kesulitan dan kemampuan seseorang untuk mengatasi kesulitan. Seseorang yang mempunyai tingkat adversity quotient tinggi memiliki dukungan untuk tetap berkembang, adanya keuletan, ketekunan, kreativitas, keberanian mengambil resiko, ketabahan, motivasi, serta mempunya kekuatan terhadap kesulitan dan tanggung jawab yang tinggi untuk tetap berkembang (Fadilah, 2018).

Penelitian yang dilakukan Sandeep Singh (2017), tentang Affect of Adversity Quotient on The Occupational Stress of IT
Managers India dengan 102 responden mendapatkan hasil penelitian yaitu ada hubungan yang signifikan antara adversity quotient dengan stres pada Manager IT di India.

Penelitian yang dilakukan Ferdiana (2019), tentang Hubungan Adversity Quotient dan Stres Akademik Mahasiswa yang mengerjakan Skripsi di Universitas Muhammadiyah Malang dengan 263 responden didapatkan hasil penelitian yaitu adanya hubungan negatif signifikan antara adversity quotient dengan stres akademik $(\mathrm{r}=-0,622 ; \mathrm{p}$ value $=0,000)$ hal ini menunjukkan semakin tinggi adversity quotient yang dimiliki oleh mahasiswa maka semakin rendah stres akademik mahasiswa. Sebaliknya semakin rendah adversity quotient maka semakin tinggi stres akademik mahasiswa. Adversity quotient dengan stres akademik memiliki sumbangan sebesar $38,7 \%$ dan sisanya $61,3 \%$ ditentukan oleh variabel lain. Dan hasil penelitian adversity quotient yang tinggi sebesar $(54,4 \%)$ dan stres akademik yang dimiliki mahasiswa yang mengerjakan skripsi dalam kategori rendah $(56,3 \%)$

Penelitian yang dilakukan oleh Wartinah (2018) tentang Hubungan Tingkat Stres antara Mahasiswa yang bekerja dan tidak bekerja dengan Prestasi Akademik pada Mahasiswa S1 manajemen 
keuangan Universitas Pamulang dari 132 responden, 73 mahasiswa yang bekerja dan 59 mahasiswa yang tidak bekerja. Mahasiswa yang bekerja mengalami stres berat sebanyak 5 mahasiswa $(6,8 \%)$, dan mahasiswa yang tidak bekerja yang mengalami stres berat sebanyak 2 mahasiswa (3,4\%).Berdasarkan studi pendahuluan, pada tanggal 10 Februari 2020 telah dilakukan wawancara pada 10 mahasiswa Program B Keperawatan di STIKes Widya Dharma Husada yang bekerja. Didapatkan hasil bahwa 7 mahasiswa (70\%) mengatakan memiliki tingkat stres karena kesulitan dalam menghadapi masalah antara bekerja dan kuliah, seperti pembagian waktu dalam bekerja dengan menyelesaikan tugas kuliah tepat waktu. Hingga sulit meluangkan waktu untuk beristirahat. Dan 3 mahasiswa (30\%) mengatakan mampu mengatasi kesulitan yang dihadapi dalam bekerja maupun kuliah. Walaupun sering mengorbankan salah satunya, misal tidak hadir kuliah akibat pekerjaan, atau sebaliknya. Serta mengantisipasi konsekuensi dari apa yang telah diputuskan. Berdasarkan ulasan tersebut, maka peneliti tertarik untuk melakukan penelitian mengenai "Hubungan Adversity Quotient, dan Kemampuan Berpikir Kritis dengan Stres pada Mahasiswa program b Keperawatan di STIKes Widya Dharma Husada Tangerang yang Sudah Bekerja”.
Penelitian ini bertujuan untuk mengetahui hubungan antara adversity quotient dan kemampuan berpikir kritis dengan stres pada mahasiswa program B Keperawatan di STIKes Widya Dharma Husada Tangerang yang sudah bekerja

\section{METODE}

Jenis penelitian yang digunakan yaitu analitik dengan pendekatan cross sectional. Penelitian ini dilaksanakan di STIKes Widya Dharma Husada Tangerang, waktu penelitian 02 Mei 2020, Populasi dalam penelitian ini adalah Mahasiswa program B Keperawatan di STIKes Widya Dharma Husada Tangerang berjumlah 208 mahasiswa dengan sampel 91 responden. Pengambilan sampel menggunakan cara non probability sampling dengan teknik purposive sampling. Pengumpulan data dalam penelitian ini menggunakan angket (kuesioner). Analisis data yang digunakan yaitu analisis univariat dan bivariat dengan menggunakan uji chi square dengan tingkat kemaknaan 95\% $(\alpha<0,05)$.

\section{HASIL}

Hasil penelitian antara Adversity Quotient, dan Kemampuan Berpikir Kritis dengan Stres, seperti berikut : 
Tabel 1. Distribusi Frekuensi Berdasarkan Karakteristik Responden di STIKes Widya Dharma Husada Tangerang yang sudah bekerja $(n=96$

\begin{tabular}{lcc} 
& ) & \\
\hline $\begin{array}{l}\text { Karakteristik } \\
\text { Responden }\end{array}$ & Jumlah & Presentase (\%) \\
\hline Usia & 5 & 5 \\
Remaja akhir & 41 & 43 \\
Dewasa awal & 41 & 43 \\
Dewasa akhir & 9 & 9 \\
Lansia awal & & \\
Jenis Kelamin & 58 & 60 \\
Perempuan & 38 & 40 \\
Laki-laki &
\end{tabular}

Tabel 2 Distribusi Frekuensi Adversity Quotient responden di STIKes Widya Dharma Husada Tangerang yang sudah bekerja $(n=96)$

\begin{tabular}{ccc}
\hline Adversity Quotient & Jumlah & Presentase (\%) \\
\hline Tinggi & 30 & 31 \\
Sedang & 48 & 50 \\
Rendah & 18 & 19 \\
Total & 96 & 100 \\
\hline
\end{tabular}

Sumber: (Data Primer, 2020)

Tabel 3 Distribusi Frekuensi Kemampuan Berpikir Kritis di STIKes Widya Dharma Husada Tangerang yang sudah bekerja $(\mathrm{n}=96)$

\begin{tabular}{lcc}
\hline Berpikir Kritis & Jumlah & $\begin{array}{c}\text { Presentase } \\
(\%)\end{array}$ \\
\hline Baik & 35 & 36,5 \\
Kurang Baik & 61 & 63,5 \\
Total & 96 & 100 \\
\hline
\end{tabular}

Sumber: (Data Primer, 2020)

Tabel 4 Distribusi Frekuensi Stres di STIKes Widya Dharma Husada Tangerang yang sudah bekerja $(n=96)$

\begin{tabular}{lcc}
\hline \multicolumn{1}{c}{ Stres } & Jumlah & Presentase (\%) \\
\hline Ringan & 28 & 29 \\
Sedang & 51 & 53 \\
Berat & 17 & 18 \\
Total & 96 & 100 \\
\hline \multicolumn{2}{c}{ Sumber: (Data Primer, 2020) }
\end{tabular}

Sumber: (Data Primer, 2020) 
Tabel 5 Hasil Analisis Hubungan Adversiy Quotient Dengan Stres pada mahasiswa program b keperawatan di STIKes Widya Dharma Husada Tangerang yang sudah bekerja

\begin{tabular}{cccccccccccc}
\hline \multicolumn{10}{c}{ Stres } \\
\hline $\begin{array}{c}\text { Adversity } \\
\text { Quotient }\end{array}$ & Ringan & Sedang & Berat & Total & $\begin{array}{c}\text { OR } \\
\mathbf{9 5 \%} \\
\text { CI) }\end{array}$ & $\begin{array}{c}\boldsymbol{P} \\
\text { Value }\end{array}$ \\
\hline & $\mathbf{F}$ & $\mathbf{\%}$ & $\mathbf{F}$ & $\mathbf{\%}$ & $\mathbf{F}$ & $\mathbf{\%}$ & $\mathbf{F}$ & $\mathbf{\%}$ & & \\
Tinggi & 13 & 43,3 & 10 & 33,3 & 7 & 23,3 & 30 & 100 & 1.780 & 0.004 \\
Sedang & 8 & 16,7 & 35 & 72,9 & 5 & 10,4 & 48 & 100 & & \\
Rendah & 7 & 38,9 & 6 & 33,3 & 5 & 27,8 & 18 & 100 & & \\
\hline
\end{tabular}

Sumber: (Data Primer, 2020)

Tabel 6 Hasil Analisis Hubungan Kemampuan Berpikir Kritis

Dengan Stres pada mahasiswa program b keperawatan di STIKes Widya Dharma Husada Tangerang yang sudah bekerja

\begin{tabular}{lcccccccccc}
\hline \multicolumn{10}{c}{ Stres } \\
$\begin{array}{l}\text { Kemampuan } \\
\text { Kerpikir }\end{array}$ & Ringan & Sedang & Berat & Total & $\begin{array}{c}\text { OR } \\
\mathbf{( 9 5 \%} \\
\text { Kritis }\end{array}$ & $\begin{array}{c}\boldsymbol{P} \\
\text { Value }\end{array}$ \\
\hline & F & $\mathbf{\%}$ & $\mathbf{F}$ & $\mathbf{\%}$ & $\mathbf{F}$ & $\mathbf{\%}$ & $\mathbf{F}$ & $\mathbf{\%}$ & & \\
Baik & 16 & 45,7 & 16 & 45,7 & 3 & 8,6 & 35 & 100 & 1,224 & 0.015 \\
Kurang Baik & 12 & 19,7 & 35 & 57,4 & 14 & 23,0 & 61 & 100 & & \\
\hline \multicolumn{8}{c}{ Sumber: (Data Primer, 2020) }
\end{tabular}

\section{PEMBAHASAN}

Berdasarkan hasil distribusi frekuensi karakteristik responden di STIKes Widya Dharma Husada Tangerang menunjukkan bahwa hampir tidak ada responden yang berusia remaja akhir (17-25 tahun) yaitu 5 responden (5\%), sedangkan hampir setengah responden berusia dewasa awal (26-35 tahun) yaitu 41 responden (43\%), dan berusia dewasa akhir (36-45 tahun) yaitu 41 responden (43\%). Peneliti menyimpulkan bahwa lebih banyak responden yang berusia dewasa awal (2635 tahun) dan dewasa akhir (36-45 tahun). Dan diperoleh hasil bahwa lebih dari setengah responden berjenis kelamin perempuan sebanyak 58 responden (60\%), sedangkan hampir setengah responden yang berjenis kelamin laki-laki yaitu 38 responden (40\%). Peneliti menyimpulkan bahwa responden yang berjenis kelamin perempuan lebih banyak dibanding laki-laki karena di tempat penelitian saya yaitu STIKes Widya Dharma Husada Tangerang dengan kriteria jurusan keperawatan, mayoritas lebih banyak mahasiswa yang berjenis kelamin perempuan daripada laki-laki.

Berdasarkan hasil distribusi frekuensi adversity quotient responden di STIKes Widya Dharma Husada Tangerang 
menunjukkan bahwa hampir setengah responden memiliki adversity quotient sedang sebanyak 48 responden (50\%), sedangkan sebagian kecil memiliki adversity quotient rendah sebanyak 18 responden (19\%).

Berdasarkan hasil distribusi frekuensi kemampuan berpikir kritis responden di STIKes Widya Dharma Husada Tangerang menunjukkan bahwa lebih dari setengah responden memiliki kemampuan berpikir kritis kurang baik sebanyak 61 responden $(63,5 \%)$.

Berdasarkan hasil distribusi frekuensi stres responden di STIKes Widya Dharma Husada Tangerang menunjukkan bahwa lebih dari setengah responden mengalami stres sedang sebanyak 51 responden (53\%), sedangkan sebagian kecil responden mengalami stres ringan sebanyak 17 responden (18\%).

Berdasarkan hasil analisis hubungan adversity quotient dengan stress pada mahasiswa program b keperawatan di STIKes Widya Dharma Husada Tangerang yang sudah bekerja menunjukkan bahwa diantara responden yang mengalami stres ringan, lebih banyak terdapat pada responden yang memiliki adversity quotient tinggi sebanyak 13 responden $(43,3 \%)$, dibandingkan dengan responden yang mengalami stres berat dengan adversity quotient tinggi sebanyak 7 responden $(23,3 \%)$.

Pada hasil uji statistik dengan menggunakan uji Chi Square diperoleh $P$ Value $=0,004(P$ value $<\alpha=0,05)$ dengan nilai OR 1,780 yang berarti bahwa responden yang memiliki adversity quotient rendah, 1,780 kali lebih besar mengalami stres berat dibandingkan dengan responden yang memiliki adversity quotient tinggi. Hal tersebut menunjukkan ada hubungan variabel adversity quotient dengan stres.

Penelitian ini sejalan dengan penelitian yang dilakukan oleh Juwita tahun 2017. Penelitian ini dilakukan pada 35 orang mahasiswa semester IV prodi Bimbingan dan Konseling IAIN Langsa, menunjukkan bahwa korelasi rx1y sebesar -0.438 pada taraf signifikan $\mathrm{p}=0.004$. artinya ada korelasi negatif yang signifikan antara adversity quotient dengan stres. Hasil uji statistik menggunakan uji regresi ganda didapatkan koefisien $r=0.484$; dengan $p$ value $=0.014$ berarti $p$ value $<0,050$. Sehingga terdapat hubungan signifikan negatif antara adversity quotient dengan stres pada mahasiswa. 
Peneliti dapat menyimpulkan bahwa semakin tinggi adversity quotient mahasiswa maka akan semakin rendah stres terhadap mahasiswa, begitupun sebaliknya semakin rendah adversity quotient mahasiswa maka akan semakin tinggi stres terhadap mahasiswa.

Berdasarkan hasil analisis hubungan kemampuan berpikir kritis dengan stres pada mahasiswa program $b$ keperawatan di STIKes Widya Dharma Husada Tangerang yang sudah bekerja menunjukkan bahwa diantara responden yang mengalami stres berat, lebih banyak terdapat pada responden dengan kemampuan berpikir kritis kurang baik sebanyak 14 responden $(23,0 \%)$ dibandingkan dengan responden yang memiliki kemampuan berpikir kritis baik sebanyak 3 responden $(8,6 \%)$.

Pada hasil uji statistik dengan menggunakan Chi Square diperoleh $p$ value $=0,015$ dengan nilai OR 1,224 yang berarti bahwa responden yang memiliki kemampuan berpikir kritis kurang baik, berisiko 1,224 kali lebih besar untuk mengalami stres berat dibandingkan dengan responden yang memiliki kemampuan berpikir kritis baik. Hal tersebut menunjukkan ada hubungan variabel kemampuan berpikir kritis dengan stres.

Penelitian ini sejalan dengan penelitian yang dilakukan oleh Maizar tahun 2017. Penelitian ini dilakukan pada 171 mahasiswa, menunjukkan bahwa jumlah kecenderungan berpikir kritis responden yang baik lebih besar dibandingkan yang kurang baik. Hasil uji statistik diperoleh kemampuan berpikir kritis mahasiswa ilmu keperawatan UIN Syarif Hidayatullah Jakarta dalam kategori baik $(65,5 \%)$ dan kurang baik $(34,5 \%)$.

Peneliti menyimpulkan bahwa jika kemampuan berpikir kritis mahasiswa dalam kategori baik, maka semakin ringan tingkat stres. Begitupun sebaliknya jika kemampuan berpikir mahasiswa kurang baik, maka semakin berat tingkat stres yang dialami.

\section{KESIMPULAN}

Teridentifikasi hasil penelitian dengan menggunakan uji Chi Square diperoleh $P$ Value $=0,004(P$ value $<\alpha=0,05)$ dengan nilai OR 1,780 yang berarti bahwa responden yang memiliki adversity quotient rendah, 1,780 kali lebih besar mengalami stres berat dibandingkan dengan responden yang memiliki 
adversity quotient tinggi. Hal tersebut menunjukkan ada hubungan variabel adversity quotient dengan stres. Teridentifikasi Pada hasil uji statistik dengan menggunakan Chi Square diperoleh $p$-value $=0,015$ dengan nilai OR 1,224 yang berarti bahwa responden yang memiliki kemampuan berpikir kritis

\section{DAFTAR PUSTAKA}

Abdullah, N.A.C \& Dan, S.M. (2011). A Study on Stres Level Among Part-time Students in a Higher institution in Kuala Lumpur Malaysia. Journal Global Management, University Utara Malaysia, Vol.3, No.1.

Ambarwati, putri dewi, et al. (2017). Gambaran Stres Pada Mahasiswa. Magelang (Jurnal) Available at URL: http://103.97.100.145/index.ph $\mathrm{p} / \mathrm{JKJ} /$ article/view/4466/4081

(Diakses pada 28 Januari 2020)

American Pshycological Association. (2013). Stress In America: Missing the Health Care Connection. (Diakses pada 23 Januari 2020)

Basri, A Said Hasan. (2017). Prokrastinasi Akademik Mahasiswa Ditinjau dari Religiusitas. Universitas Sunan Kalijaga. Available at URL: $\quad$ http://ejournal.uinsuka.ac.id/dakwah/hisbah/artic le/download/1201/1041 kurang baik, berisiko 1,224 kali lebih besar untuk mengalami stres berat dibandingkan dengan responden yang memiliki kemampuan berpikir kritis baik. Hal tersebut menunjukkan ada hubungan variabel kemampuan berpikir kritis dengan stres.

(Diakses pada tanggal 22 Januari 2020)

Hidayat, B.A. (2012). Hubungan Tingkat Stres dengan Kejadian Insomnia Pada Mahasiswa Program Studi Ilmu Keperawatan Universitas Diponegoro. Skripsi. Fakultas Kedokteran Universitas Diponegoro Available at URL: http://eprints.undip.ac.id/3316 0/ (Diakses pada 27 Januari 2020)

Mustafa, M.Z et al. (2009). Kajian Stres Dalam Kalangan Pelajar Wanita Program Sarjana Muda Kejuruan di University Tun Hussein on Malaysia. Kuala Lumpur

Salam, Dahlia Binti. (2015). Perbedaan Tingat Stres Mahasiswa Part-time Study Ditinjau dari Status Pernikahan. Universitas Islam Negeri Sultan Syarif Kasim Riau. Available at URL: http://repository.uinsuska.ac.id/6957/

Syamsuddin. (2017). Komparasi Tingkat Stres Antara Mahasiswa Input MA dan Input SMA Jurusan 
Manajemen Pendidikan Islam

Fakultas Tarbiyah dan

Keguruan. Uin Alaudin

Makassar. Available at URL:

http://journal.uin-

alauddin.ac.id/index.php/klm/a rticle/view/4490/4107

Yanhi, Christy. (2015). Gambaran Tingkat Stres Angkatan XVIII Akademi Keperawatan Husada Karya Jaya Terhadap Mata Kuliah Riset Keperawatan. Jakarta. Available at URL: http://ejurnal.husadakaryajaya. ac.id/index.php/JAKHKJ/articl e/view/12/11 (Diakses pada 25 Januari 2020. 
